\title{
Ammonium uptake by phytoplankton cells on a filter: a new high-resolution technique
}

\author{
J. S. Parslow ${ }^{1}$, P. J. Harrison ${ }^{1,2} \&$ P. A. Thompson ${ }^{1}$ \\ Departments of ${ }^{1}$ Oceanography and ${ }^{2}$ Botany, University of British Columbia, Vancouver, British Columbia V6T 1 W5, Canada
}

\begin{abstract}
Ammonium uptake by the marine diatom Thalassiosira pseudonana was measured by trapping chemostat-grown cells on an in-line filter and following changes in the concentration of ammonium pulses pulled across the filter. Over time intervals longer than $1 \mathrm{~min}$, this technique yielded results comparable to those obtained using conventional techniques on cell suspensions. The new technique also allowed changes in uptake kinetics within the first minute of exposure to ammonium to be resolved. Saturated uptake rates were highest $\left(26 \mathrm{~d}^{-1}\right)$ within the first $15 \mathrm{~s}$, and declined to $11 \mathrm{~d}^{-1}$ after $1 \mathrm{~min}$. The affinity for ammonium remained constant at $17 \mathrm{~d}^{-1} \mu \mathrm{M}^{-1}$. Implications of these results for models of uptake and assimilation, and possible adaptation of the technique for use in the field, are discussed.
\end{abstract}

\section{INTRODUCTION}

Macronutrients such as nitrogen and phosphorus are believed to limit phytoplankton production in many marine and freshwater communities; consequently the uptake kinetics of these nutrients have long been of interest to physiologists and ecologists (for review see McCarthy 1981, Cembella et al. 1984). With the discovery of rapid changes in uptake parameters in cells exposed to sudden changes in nutrient concentration, it has become necessary to follow uptake transients on time scales of minutes or even seconds (Conway et al. 1976, Goldman \& Glibert 1982). Whether based on dissolved nutrient disappearance, or isotopic incorporation, these studies have traditionally been labourintensive involving the filtration of numerous point samples taken at short time intervals.

To simplify the study of uptake transients, techniques have been developed which combine an autoanalyzer and an in-line filter to permit the continuous or semi-continuous monitoring of dissolved nutrient concentrations in cell suspensions (Conway et al. 1976). Cells accumulating on such an in-line filter can remove nutrient from the medium flowing past them and consequently distort the measured uptake rates. To eliminate this artifact we developed a modification to keep the filter cell-free (Parslow et al. 1984a). We have subsequently investigated the possibility that cells might be deliberately concentrated on an in-line filter, and their uptake rate measured as the decrease in dissolved nutrient in a cell-free standard flowing past them.

In this paper, we describe a simple experimental procedure for measuring uptake rates as a decrease in dissolved nutrient concentrations across cells collected on an in-line filter. This procedure was used to measure ammonium uptake rates by the marine diatom Thalassiosira pseudonana on a variety of time scales; the results are compared with rates obtained using more conventional techniques on cell suspensions. The technique allows greater sensitivity and sharper resolution in time compared with previous results (Parslow et al. 1985); the implications of these new data for ammonium uptake mechanisms in $T$. pseudonana are also discussed.

\section{MATERIALS AND METHODS}

The experimental assembly is shown in Fig. 1. Two 3-way valves, $V_{A}$ and $V_{B}$, allow one to switch among reservoirs containing ammonium-free medium or wash, an ammonium standard of chosen concentration, and a culture sample. To reduce smearing and allow precise timing of ammonium pulses, electric solenoid valves (General Valve Corp. 1-43-900) were used.

A standard procedure was used for uptake measurements. Before inserting the filter in line, the valve $V_{A}$ 

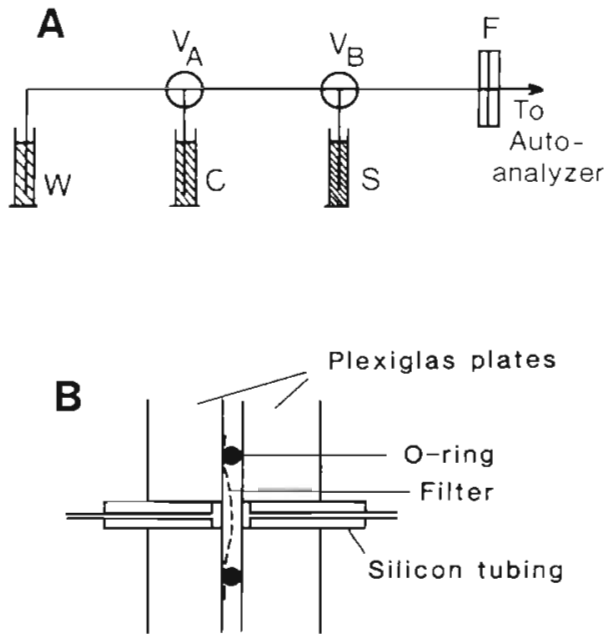

Fig. 1. (A) Apparatus used to measure uptake by cells trapped on an in-Iine filter $(F)$. Three-way valves $V_{A}$ and $V_{B}$ are used to switch among ammonium-free medium (W), culture (C) and an ammonium standard (S). (B) Section through in-line filter assembly

was switched on to pre-load the tubing between the culture sample and $V_{A}$ with cells. $V_{A}$ was then switched off to clear cells from the tubing between $V_{A}$ and the filter insertion point. After the filter was connected in-line and washed for several minutes with ammonium-free medium, $V_{B}$ was switched on and off to generate a standard peak of chosen duration without cells on the filter. $V_{A}$ was then switched on and cells were loaded onto the filter for a measured period. After switching $V_{A}$ off and waiting 30 s to clear cells from the tubing, $V_{B}$ was used to run standard pulses of the chosen duration across the cells collected on the filter.

The in-line filter used in these experiments (Fig. $1 \mathrm{~B}$ ) consists simply of 2 plates of Plexiglas clamped together, on either side of a $1 \mu \mathrm{m}$ polycarbonate Nuclepore ${ }^{\circledR}$ filter (chosen because it does not release ammonium), with an $\mathrm{O}$-ring $(9 \mathrm{~mm}$ dianeter and $1 \mathrm{~mm}$ cross-sectional diameter) forming a seal around the filter. The O-ring is centered on opposing $3 \mathrm{~mm}$ holes drilled in the Plexiglas sheets. Short lengths of silicone tubing ( $4 \mathrm{~mm}$ o.d., $0.5 \mathrm{~mm}$ i.d.) forced into these holes allow coupling to the polyethylene tubing used to connect the components in Fig. 1 A. Cells were always loaded from the opposite side to the O-ring, as this allowed the full area inside the O-ring to be used for filtration.

Uptake rates were calculated from the difference between standard peaks with and without cells on the filter, as described in the 'Results' section. Two types of measurements are reported here. Standard pulses of long duration ( $7 \mathrm{~min}$ ) allowed a continuous estimate of uptake rates after the first $2 \mathrm{~min}$, when smearing by the autoanalyzer could be ignored. Standard pulses of short duration ( $15 \mathrm{~s}, 30 \mathrm{~s}$ and $1 \mathrm{~min}$ ) allowed estimates of uptake rates within the first minute of exposure to external ammonium. These uptake rates were compared with uptake rates by cell suspensions measured using the self-cleaning in-line filter described previously (Parslow et al. 1984a).

The Thalassiosira pseudonana $(3 \mathrm{H})$ culture used in these uptake experiments was grown at steady-state in an ammonium-limited chemostat at a dilution rate of $0.5 \mathrm{~d}^{-1}$. The chemostat was operated under conditions described previously (Parslow et al. 1984b) using artificial seawater medium (ESAW; Harrison et al. 1980) with nitrate replaced by $50 \mu \mathrm{M}$ ammonium chloride, under continuous irradiance $\left(80 \mu \mathrm{Ein} \mathrm{m}^{-2} \mathrm{~s}^{-1}\right)$ and at $18{ }^{\circ} \mathrm{C}$. The ammonium-saturated growth rate under these conditions was $1.7 \mathrm{~d}^{-1}$ (Parslow et al. 1984b).

\section{RESULTS}

The formulae for converting changes in concentration $\Delta \mathrm{S}$ across a filter loaded with cells into uptake rates per cell, and equivalent disappearance rates in cell suspensions, can be derived as follows. If $Q$ is the uptake rate per cell ( $\mu$ g-at cell $\left.{ }^{-1} \mathrm{~h}^{-1}\right)$, and there are $\mathrm{N}$ cells on the filter, the nutrient taken up in a small time interval $\delta \mathrm{t}$ is $\mathrm{Q} N \delta \mathrm{t} \mu \mathrm{g}$-at. This nutrient is removed from a volume $v \delta t$ where $v$ is the flow rate across the filter (2.4 ml min $\mathrm{min}^{-1}$ in our experiments). The change in concentration is therefore $\Delta \mathrm{S}=\mathrm{QN} \delta \mathrm{t}(\mathrm{v} \delta \mathrm{t})^{-1}=$ $\varrho \mathrm{Nv}^{-1}$. Because cells were loaded onto the filter at the same flow rate $v$, the number of cells on the filter equals $\mathrm{c} v \mathrm{~T}$, where $\mathrm{c}$ is the cell density in suspension and $\mathrm{T}$ is the loading period. Substituting for $\mathrm{N}=\mathrm{c} \vee \mathrm{T}$ yields

OI

$$
\Delta S=\varrho \subset T
$$

$$
\mathrm{Q}=\Delta \mathrm{S}(\mathrm{C} T)^{-1}
$$

The equivalent disappearance rate in suspension equals $\mathrm{QC}$, or $\Delta \mathrm{S} \mathrm{T}^{-1}$. If $\mathrm{PN}$ is the concentration of paritculate cell nitrogen in suspension ( $\mu$ g-at $1^{-1}$ ), the specific uptake rate $\mathrm{V}$ is given by

$$
\begin{aligned}
\mathrm{V} & =\mathrm{gcPN^{-1 }} \\
& =\Delta \mathrm{ST}^{-1} \mathrm{PN}^{-1}
\end{aligned}
$$

This argument avoids entirely the problem of the spatial variation in ammonium concentration among cells on the filter. The uptake rates $Q$ and $V$ obtained from the above formulae represent averages over cells on the filter. If the change in concentration $\Delta S$ is small compared with the standard concentration $\mathrm{S}_{1}$, one might argue that the cells are seeing similar concentrations and have similar uptake rates. When $\Delta \mathrm{S} / \mathrm{S}_{\mathrm{i}}$ is not small, one can try to correct for the effects of the 
nutrient gradient, given assumptions about the shape of the uptake vs substrate curve. It is conceivable that the spatial distribution of cells on the filter and of the subsequent flow of standard could be such as to severely distort uptake estimates. Equally, it is possible that cells on a filter are harmed by the physical environment, or experience a different micro-spatial nutrient regime. We have tested for these effects directly by comparing uptake by cells on a filter with uptake by cells in suspension.

In Fig. 2, estimates of ammonium uptake rates by Thalassiosira pseudonana, between 2 and 6 min after

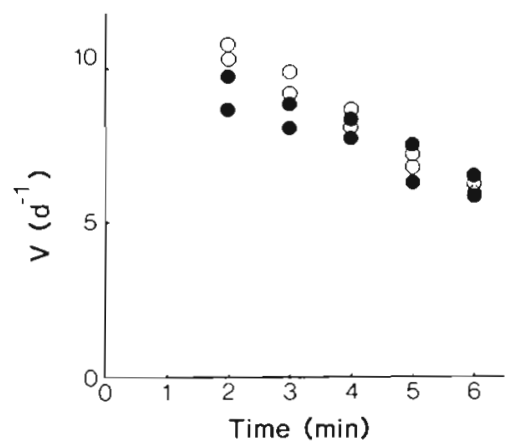

Fig. 2. N-specific ammonium uptake rates $\left(d^{-1}\right)$ vs time for chemostat cells initially subjected to a $4 \mu \mathrm{M}$ ammonium perturbation. $(O)$ cells trapped on a filter; $(\bullet)$ cells in suspension

onset of a $4 \mu \mathrm{M}$ ammonium pulse, are presented. One set was obtained using the self-cleaning filter technique (Parslow et al. 1984a) to continuously monitor the disappearance of external ammonium in duplicate $50 \mathrm{ml}$ samples of culture, perturbed to $4 \mu \mathrm{M}$ at $\mathrm{t}=0$. Uptake rates were calculated from the slope of the disappearance traces (Fig. 3A) at $\mathrm{t}=2,3,4,5$ and $6 \mathrm{~min}$. The second set of uptake rates in Fig. 2 were obtained by applying Eq. (3) to the decrease in ammonium concentration in a $4 \mu \mathrm{M}$ standard across filters loaded with culture for $2 \mathrm{~min}$ (Fig. 3B). The uptake rates estimated using cells in suspension are initially slightly lower than those estimated for cells on filters, but the difference is small, and the decline in uptake rate with time for the 2 cultures is similar. The initial difference may be partly accounted for by an additional time lag of $15 \mathrm{~s}$ between the addition of the ammonium pulse and cells reaching the in-line filter in the cell suspension technique (Parslow et al. 1984a).

Previous results (Parslow et al. 1985) and results reported later in this section show that all uptake rates in Fig. 2 are close to being a mmonium saturated. However, the changes in ammonium concentration with time experienced by cells in suspension and those experienced by cells on a filter, are quite different (Fig. 3A, B). Cells in suspension experience a steadily declining ambient concentration, while cells on a filter
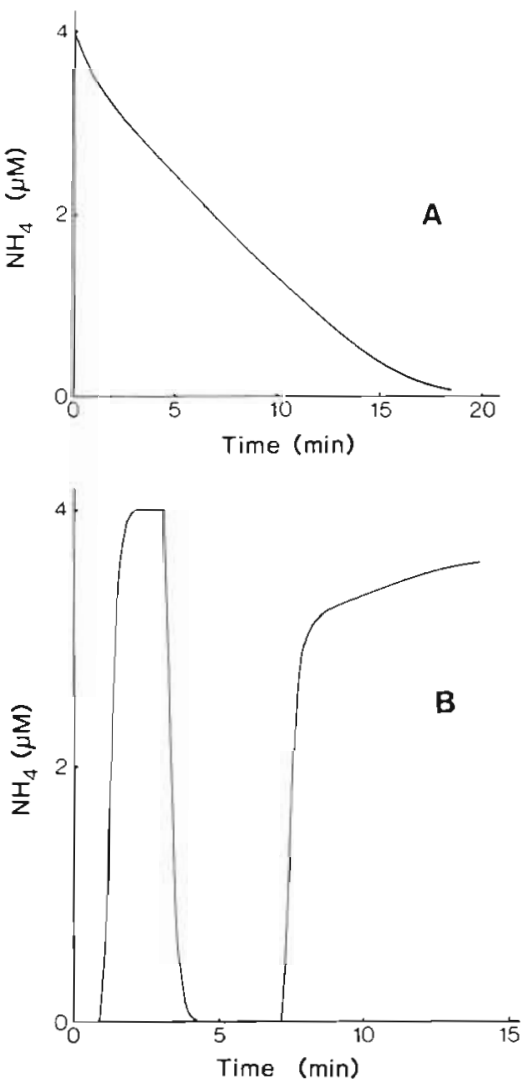

Fig. 3. (A) Continuous record of ambient ammonium concentration vs time following a $4 \mu \mathrm{M}$ addition to a chemostat cell suspension. (B) Continuous record of ammonium concentra tion vs time for a $4 \mu \mathrm{M}$ ammonium pulse without (1st peak) and with (2nd peak) cells trapped on an in-line filter

see a slowly increasing, but relatively constant, ambient concentration. For lower ammonium perturbations, where uptake rates are affected by both ambient concentration and changing internal status, results obtained from cells on a filter are simpler to interpret.

The argument of the preceding paragraph is well illustrated by Fig. 4, which shows uptake rates obtained by exposing cells on filters to 6 min pulses of ammonium standards at concentrations ranging from 0.15 to $8 \mu \mathrm{M}$. Each point represents the mean of duplicate traces obtained with samples taken from the chemostat on different days. The standard error based on mean square differences between duplicates was $0.18 \mathrm{~d}^{-1}$ for the 3 lower perturbation levels, and $0.45 \mathrm{~d}^{-1}$ for the 4 higher levels. Two characteristics of the response of Thalassiosira pseudonana to ammonium pulses are clear in Fig. 4. The uptake rate declines with time for cells exposed to ambient concentrations of $1.0 \mu \mathrm{M}$ or higher, and uptake rates after 2 min appear to be saturated at $2 \mu \mathrm{M}$. However, in cells exposed to concentrations of $0.5 \mu \mathrm{M}$ or less, the uptake rate is independent of exposure time. 


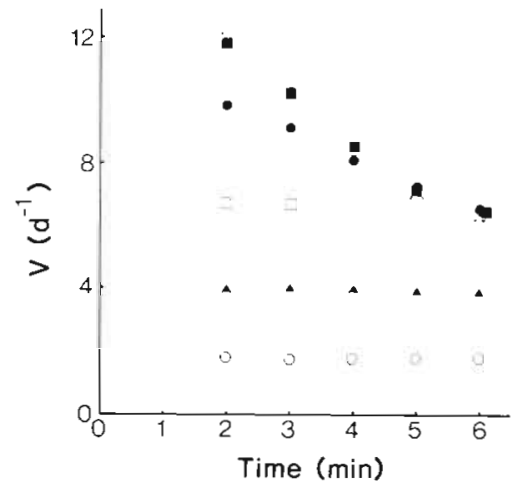

Fig. 4. N-specific ammonium uptake rates $v s$ time for chemostat cells on an in-line filter subjected to 6 min standard pulses of concentration: $0.15 \mu \mathrm{M}(0), 0.30 \mu \mathrm{M}(\mathbf{4}), 0.52 \mu \mathrm{m}(\square)$, $1.03 \mu \mathrm{M}(\bullet), 2.0 \mu \mathrm{M}(\nabla), 4.0 \mu \mathrm{M}(\triangle), 8.0 \mu \mathrm{M}(\square)$. New cells were obtained from the chemostat for each concentration pulse that was followed for $6 \mathrm{~min}$

These same data have been replotted as $\mathrm{V}$ vs $\overline{\mathrm{S}}$ curves for equal times of exposure to ammonium pulses in Fig. 5. $\overline{\mathrm{S}}$ represents the arithmetic mean of the concentrations of the standard before and after flowing across cells on the filter. The uptake curves are coincident for $\overline{\mathrm{S}} \leqslant 0.4 \mu \mathrm{M}$, and in this region, form a straight line through the origin. Saturation of uptake occurs at values of $\overline{\mathrm{S}}$ above $0.4 \mu \mathrm{M}$, and becomes more abrupt as exposure time increases.

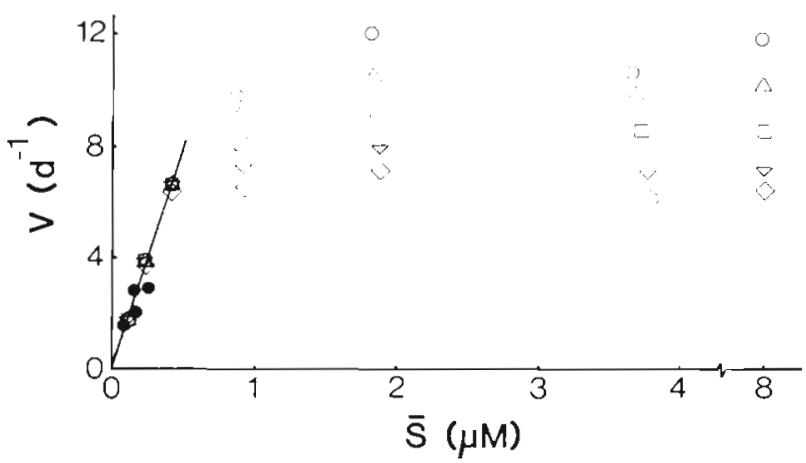

Fig. 5. Uptake rates from Fig. 4 vs average of pre-and postfilter ammonium concentrations for exposure times of: 2 min $(0), 3 \mathrm{~min}(\triangle), 4 \mathrm{~min}(\square), 5 \mathrm{~min}(\nabla)$ and $6 \mathrm{~min}(\diamond)$. The solid dots show uptake rates by cell suspensions at low concentrations

The results presented in Fig. 5 closely resemble. $V$ vs $\bar{S}$ curves for ammonium-starved batch cultures of Thalassiosira pseudonana obtained for cell suspensions using the self-cleaning in-line filter technique and the more conventional filtration of point subsamples (Parslow et al. 1985). In that study, uptake rates at low values of $\overline{\mathrm{S}}$ fell on a straight line through the origin with a slope of $18.9 \mathrm{~d}^{-1} \mu \mathrm{M}^{-1}$ for the in-line filter, and $15.1 \mathrm{~d}^{-1} \mu \mathrm{M}^{-1}$ for the point sample technique. The initial slope in Fig. 5 is $16.4 \mathrm{~d}^{-1} \mu \mathrm{M}^{-1}$. Moreover $(\mathrm{V}, \mathrm{S})$ pairs calculated from the slope of the disappearance trace in Fig. 3A after 17 min, when $\mathrm{S}<0.3 \mu \mathrm{M}$, also fall close to this straight line (Fig. 5). We conclude that $T$. pseudonana cells on a filter show the same substrate dependence of uptake, as well as the same transients in saturated uptake rate, as cells in suspension.

As we noted previously, signal smearing due to mixing within the autoanalyzer hinders attempts to measure uptake rates over intervals shorter than $1 \mathrm{~min}$ using the self-cleaning filter technique. However, using the cells-on-the-filter technique, one can exploit this smearing in the following way. Very short standard pulses, $15 \mathrm{~s}$ or less in duration, are smeared so extensively that no memory of the pulse shape is retained, and the signal peak height is proportional to the total integrated ammonium in the incoming pulse. By measuring the relative peak heights of $15 \mathrm{~s}$ pulses of known ammonium standards with and without cells on the filter, one can compute the total ammonium taken up, and deduce an average uptake rate over this $15 \mathrm{~s}$ interval.

Uptake rates by Thalassiosira pseudonana cells were calculated in this way for pulses of $15 \mathrm{~s}, 30 \mathrm{~s}$ and $1 \mathrm{~min}$ duration. The results are plotted as uptake rates vs the arithmetic mean of initial and final concentrations (Fig. 6). Qualitatively, these curves represent extensions of the pattern observed for longer exposure

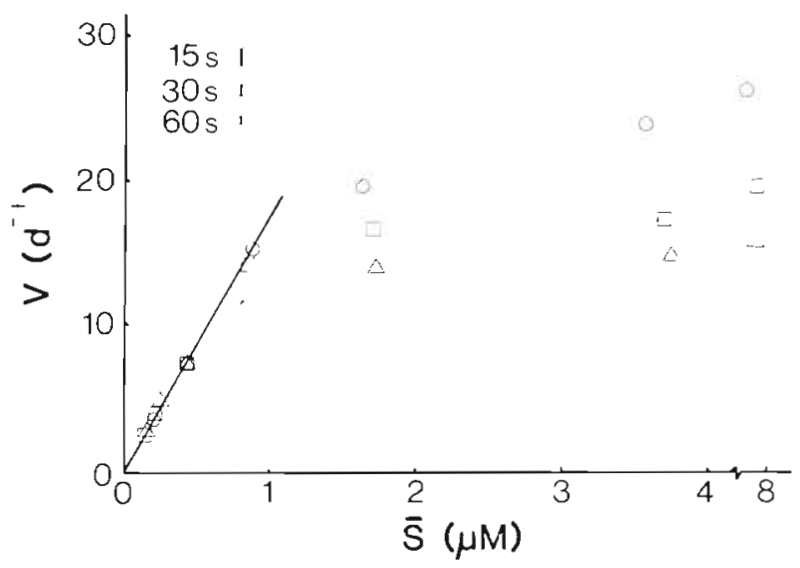

Fig. 6. N-specific ammonium uptake rates for chemostat cells on an in-line filter subjected to standard pulses of $15 \mathrm{~s}(0)$, $30 \mathrm{~s}(C)$ and $1 \mathrm{~min}(\Delta), v s$ average of pre- and post-filter ammonium concentrations. The vertical bars represent 2 SE, based on analysis of variance between duplicates

periods in Fig. 5. The initial slope is again constant and equals $17.5 \mathrm{~d}^{-1} \mu \mathrm{M}^{-1}$, essentially the same as for longer exposure periods. Saturated uptake rates declined from $26 \mathrm{~d}^{-1}$ for $15 \mathrm{~s}$ pulses to $20 \mathrm{~d}^{-1}$ for $30 \mathrm{~s}$ pulses and $16 \mathrm{~d}^{-1}$ for 1 min pulses. 
As the pulse duration increases from $15 \mathrm{~s}$ to $1 \mathrm{~min}$, smearing becomes relatively less important and peak height differences are determined less by average uptake rates during the pulse and more by the instantaneous uptake rate at the end of the pulse. For those possessing the equipment to routinely store and process the autoanalyzer signal digitally (e.g. Whitledge et al. 1981), it would be easy to avoid this ambiguity by integrating under peaks, thereby obtaining an exact measure of total ammonium uptake for any pulse duration. Alternatively, one could try to correct for autoanalyzer smearing and resolve the instantaneous uptake rate as a function of time during the pulse.

So far, we have implicitly assumed that smearing occurs only after the pulse has passed the filter, so that the cells see a square-wave pulse of the appropriate concentration. The pulse is generated by a solenoid valve and may be subjected to smearing as it is formed, or as it crosses the filter. It is possible that very short (15 s) pulses are smeared sufficiently that the cells see a pulse of significantly longer duration and lower concentration. The apparent increase in saturated uptake rate for $15 \mathrm{~s}$ pulses could then be an artifact, caused by a longer exposure time. Smearing of the signal by the autoanalyzer itself is so extensive as to prevent any direct observation of smearing by the solenoid valve and filter. However, we were able to estimate the latter indirectly by mathematically characterizing the smearing due to the autoanalyzer alone. This procedure is described in an appendix. We show there that the effect of the solenoid and filter can be represented as a linear, first-order process with characteristic time $\tau_{\mathrm{f}}=3.3 \mathrm{~s}$. The shape of a $15 \mathrm{~s}$ pulse as seen by cells on the filter, calculated using this time constant, is shown in Fig. 7. Theoretical calculations show that this

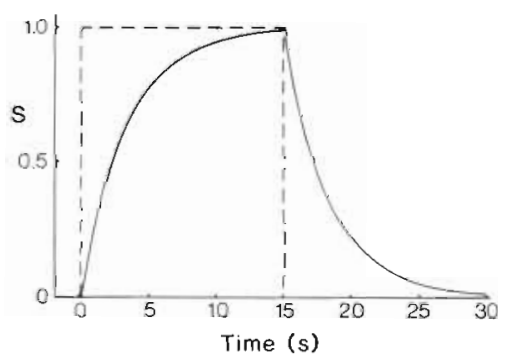

Fig. 7 . The shape of the $15 \mathrm{~s}$ anmonium pulse seen by cells on the in-line filter (solid line), due to smearing of a theoretical $15 \mathrm{~s}$ step-function (dashed line)

degree of smearing should result in uptake rates being overestimated by about $20 \%$ for $15 \mathrm{~s}$ pulses, and by less than $5 \%$ for $30 \mathrm{~s}$ pulses.

One can also attempt to correct for the autoanalyzer smearing directly, to recover the signal entering the autoanalyzer. This procedure is described in the appendix. It is not possible to completely correct for smearing, but one can obtain a signal with time resolution better than $10 \mathrm{~s}$. The correction procedure does introduce additional noise, as it involves the addition of first and second derivatives of the original signal. In Fig. 8, corrected time courses of uptake are shown for 1 min pulses of standards ranging from 0.7 to $8.0 \mu \mathrm{M}$.

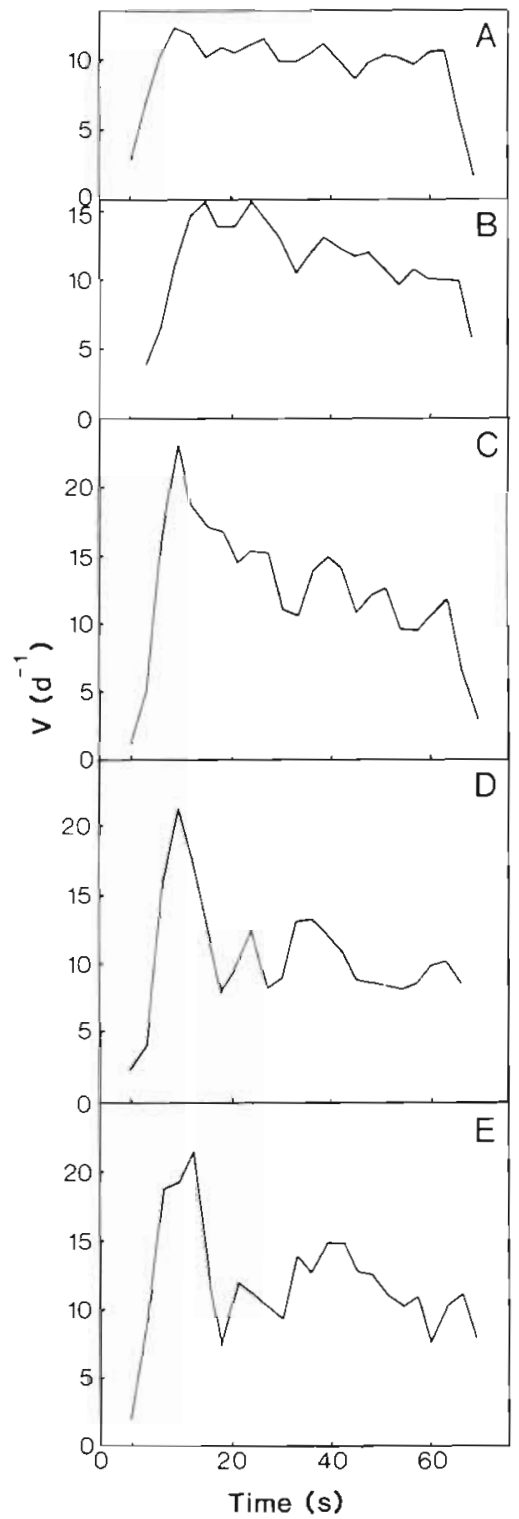

Fig. 8. N-specific ammonium uptake rates vs time within 1 min pulses of concentration: $0.7 \mu \mathrm{M}(\mathrm{A}), 1.1 \mu \mathrm{M}(\mathrm{B}), 2 \mu \mathrm{M}$

(C), $4 \mu \mathrm{M}$ (D) and $8 \mu \mathrm{M}(\mathrm{E})$, after correcting for smearing

For a standard pulse of $0.7 \mu \mathrm{M}$ (Fig. 8A), the corrected uptake rate is ca $10.7 \mathrm{~d}^{-1}$ and shows very little change with time during the pulse. This uptake rate is consistent with the average $15 \mathrm{~s}, 30 \mathrm{~s}$ and 1 min rates observed for the same value of $\overline{\mathrm{S}}(0.6 \mu \mathrm{M}$ : Fig. 6). For a 
standard pulse of $1.1 \mu \mathrm{M}$ (Fig. $8 \mathrm{~B}$ ), the uptake rate is initially higher (ca $15 \mathrm{~d}^{-1}$ ) and declines to ca $10 \mathrm{~d}^{-1}$ towards the end of the $1 \mathrm{~min}$ pulse. The uptake rate is again higher initially $\left(22.2 \mathrm{~d}^{-1}\right)$, and declines more rapidly, for a standard pulse of $2 \mu \mathrm{M}$ (Fig. $8 \mathrm{C}$ ). This trend continues for the 4 and $8 \mu \mathrm{M}$ pulses (Fig. $8 \mathrm{D}, \mathrm{E}$ ): that is, the initial burst of uptake becomes more rapid and shorter-lived at higher concentrations. We suspect that the marked oscillations in uptake rate following the initial burst are artifacts, caused by the correction procedure. However, the average uptake rate following the initial burst is remarkably constant at about $11 \mathrm{~d}^{-1}$ for all standard concentrations.

\section{DISCUSSION}

The technique described here has allowed us to resolve changes in uptake rates over time intervals of the order of 10 to $15 \mathrm{~s}$. The best resolution we have obtained by following ammonium disappearance in cell suspensions, either with continuous in-line filtration or point sampling, is ca $60 \mathrm{~s}$. These techniques are limited by the time required to mix ammonium additions and by autoanalyzer smearing or the time required for subsampling and filtration. Measuring uptake by cells on a filter also allows better precision. The sensitivity can be controlled easily by changing the number of cells loaded onto the filter, and ammonium contamination problems associated with discrete sub-sampling and point filtration are avoided. If single short pulses are run, the new technique is just as labour- and time-consuming as point sampling. However, continuous changes in uptake rate with time can be followed directly for time intervals longer than $1 \mathrm{~min}$, and for shorter intervals using the smear correction described in the appendix.

Aside from these practical considerations, the nutrient environment of cells on a filter can be manipulated in ways which are difficult or impossible for cell suspensions. In perturbation uptake experiments, cells in suspension experience a rapidly declining nutrient concentration, while cells on a filter experience a relatively constant concentration. Much more complicated mutrient transients can also be studied. We have begun experiments in which cells are exposed to a series of short nutrient pulses separated by ammonium-free wash, to study the recovery of surge uptake capacity following short exposures to ammonium.

The technique has so far been tested for a diatom only. There is reason to believe that it may be useful for more fragile forms. The stresses imposed upon cells on an in-line filter depend on the pressure drop across it, and this in turn depends on the flow rate and the filter area and porosity. The flow rate required by the auto- analyzer is quite small, and the filter surface area can be increased to reduce the pressure drop to very low levels, at the cost of an increase in smearing and poorer time resolution. If the technique can be adapted to more fragile forms, it may prove to be most useful in field studies. In preliminary trials, we have been able to concentrate 11 of a surface sample, dominated by flagellates and containing less than $1 \mu \mathrm{g} \mathrm{Chl} \mathrm{a} \mathrm{I}^{-1}$, on a $47 \mathrm{~mm}$ filter by gentle gravity filtration, and to measure significant ammonium uptake over $5 \mathrm{~min}$ intervals.

In a previous study of ammonium uptake by $\mathrm{N}$ starved Thalassiosira pseudonana, saturated uptake rates were observed to decline from ca $20 \mathrm{~d}^{-1}$ over the first minute to a long-term (10 to $30 \mathrm{~min}$ ) rate of $8 \mathrm{~d}^{-1}$ (Parslow et al. 1984b). In the present study, the time resolution was improved and saturated uptake rates were again observed to decrease as exposure time increased from $26 \mathrm{~d}^{-1}$ at $15 \mathrm{~s}$ to $11 \mathrm{~d}^{-1}$ after $1 \mathrm{~min}$. The corrected 1 min pulses (Fig. 8) show that this increase is due to a burst of uptake which becomes more rapid, and more short-lived, as the external ammonium concentration increases.

The peak observed uptake rates of $26 \mathrm{~d}^{-1}$ corresponded to uptake rates per cell of $0.08 \mathrm{pmol} \mathrm{cell}^{-1} \mathrm{~h}^{-1}$. The average cell surface area was $56 \mu \mathrm{m}^{2}$, so this represents a transport flux of $40 \mathrm{pmol} \mathrm{cm} \mathrm{cm}^{-2} \mathrm{~s}^{-1}$ across the cell membrane. It has been argued that ammonium is transported as the ionic form via uniporters using energy supplied by the cell membrane potential (Raven 1980, Wheeler 1983). Because the cell membrane capacitance is very low, the ammonium influx must be balanced by primary active transport of protons or sodium ions. The observed fluxes represent an appreciable fraction of the maximum theoretical capacity of primary active transport, estimated to be 200 pmol $\mathrm{cm}^{-2} \mathrm{~s}^{-1}$ (Raven 1980).

It has also been suggested that ammonium uptake could occur via diffusion of $\mathrm{NH}_{3}$ through the membrane, and acid-trapping within a low $\mathrm{pH}$ vacuole (Wheeler 1983). At an external pH of $8.2,6 \%$ of total ammonia is present as $\mathrm{NH}_{3}$. Given a membrane permeability for $\mathrm{NH}_{3}$ of $0.1 \mathrm{~cm} \mathrm{~s}^{-1}$ (Raven 1980) and even assuming the internal $\mathrm{NH}_{3}$ concentration is zero, the maximum possible diffusive flux is $6 \mathrm{pmol} \mathrm{cm}^{-2} \mathrm{~s}^{-1}$ for an external concentration of $1 \mu \mathrm{M}$. This is much smaller than the observed flux at this concentration.

At external concentrations below $0.5 \mu \mathrm{M}$, the observed uptake rates did not vary with time, and depended only on the external concentration in a linear fashion. The slope of this line may reflect the affinity of the transport sites for ammonium ions. However, it is also possible that the slope is affected by diffusion through an ammonium-depleted zone around the cells (Pasciak \& Gavis 1974). If one assumes spherical sym- 
metry and Fickian diffusion, the equilibrium ammonium concentration $\mathrm{S}$ at a distance $\mathrm{r}$ from the cell centre is given by

$$
S(r)=S_{0}-\left(S_{0}-S_{m}\right) r_{m} / r
$$

where $S_{0}=$ concentration at infinity; $S_{m}=$ concentration at the membrane; $r_{m}=$ cell radius. In the most favourable case, when $S_{m}=0$, the flux into the cells is $4 \pi D S_{0} r_{m}$. Using the molecular diffusion coefficient $D=10^{-5} \mathrm{~cm}^{2} \mathrm{~s}^{-1}$, cell radius of Thalassiosira pseudonana $\mathrm{r}_{\mathrm{m}}=2 \times 10^{-4} \mathrm{~cm}$, and $\mathrm{S}_{0}=0.5 \mu \mathrm{M}$, this yields a flux of 0.045 pmol cell ${ }^{-1} \mathrm{~h}^{-1}$. The observed initial slope of the $V$ vs $\mathrm{S}$ curve corresponds to a flux of $0.026 \mathrm{pmol} \mathrm{cell}^{-1} \mathrm{~h}^{-1}$ at an external concentration of $0.5 \mu \mathrm{M}$. While this is below the upper diffusion limit, the 2 figures are close, given the uncertainties in the calculation, and it seems probable that diffusion to the cell surface does influence the observed affinity. For example, if the affinity of the membrane porters was twice the calculated value, the concentration at the cell membrane would be half that at infinity, and diffusion to the cell membrane would just balance uptake.

The rapid transients in uptake rates at high external concentrations take place on 2 distinct time scales which presumably correspond to different processes affecting ammonium uptake or assimilation. The burst of rapid uptake within the first minute, which becomes faster but shorter-lived at higher external concentrations (Fig. 8), suggests the filling of some internal pool. The capacity of the pool may be indicated by the amount of ammonium taken up in excess of the $1 \mathrm{~min}$ rate. The pool capacity calculated in this way represents $7.4 \times 10^{-5} \mathrm{pg}$-at cell ${ }^{-1}$, and corresponds to an average intracellular concentration of $3 \mathrm{mM}$. This is much smaller than the ammonium storage capacity of Thalassiosira pseudonana, which is at least $40 \mathrm{mM}$ (Dortch pers. comm.).

The constancy of uptake rates at low external concentrations shows that inhibition of uptake is not a simple linear or Michaelis-Menten function of ammonium taken up. There is clearly a threshold response, with inhibition accurring only when the external concentration allows some 'sustainable' uptake rate to be exceeded. This is again consistent with a pool model, in which the sustainable rate represents the rate at which the pool is emptied, through assimilation or transfer to another compartment. The results obtained here indicate a pool-emptying rate which is initially $11 \mathrm{~d}^{-1}$, but declines to $7 \mathrm{~d}^{-1}$ after $6 \mathrm{~min}$. This decline may reflect changes in substrates associated with the pool-emptying process. The identification of these hypothetical pools and substrates must await further studies of parallel changes in intracellular levels of likely storage and assimilatory products and enzymes. The present results do offer some guide as to the time scales and magnitudes of changes to be expected.

\section{APPENDIX}

The signal $\mathrm{S}(\mathrm{t})$ produced by our autoanalyzer in response to a step change in ammonium concentration without the filter and solenoid in line is shown in Fig. 9 (solid line). (This step change was produced by manually transferring a tube from 1 small sample cup to

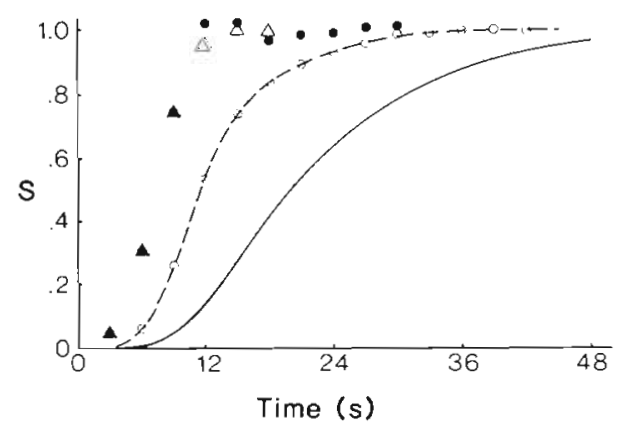

Fig. 9. Autoanalyzer signal for a step unit change in concentration (solid line), derived signal $S_{1}$ following a first-order correction with $\mathrm{r}_{1}=9.8 \mathrm{~s}$ (dashed line) and derived signal $\mathrm{S}_{2}$ following a second correction with $\tau_{2}=5.7 \mathrm{~s}$ (solid circles). Triangles correspond to a cumulative gaussian with $a=2.65$

another beside it: the transfer time is a small fraction of a second. In this discussion and in Fig. $9 \& 10$, concentrations have been normalised to give a unit step change.) The first attempt to correct this signal for smearing assumed a first-order linear response (Whitledge et al. 1981, Parslow et al. 1984a):

$$
\frac{\mathrm{dS}}{\mathrm{dt}}=\left(\mathrm{S}-\mathrm{S}_{\mathrm{i}}\right) / \tau
$$

where $S_{i}$ is the incoming signal and $\tau$ is a characteristic response time. According to Eq. (5), if $S_{1}$ undergoes a unit step increase, a plot of $\ln (1-\mathrm{S}[\mathrm{t}])$ vs t should give a straight line with slope $1 / \tau$. The log plot corresponding to the signal in Fig. 9 is asymptotically a straight line, with slope corresponding to $\tau_{1}=9.8 \mathrm{~s}$, but there is a strong initial departure from linearity (Fig. 10, solid line). Eq. (5) can be inverted to give a corrected signal:

$$
\mathrm{S}_{1}(\mathrm{t})=\mathrm{S}(\mathrm{t})+\tau_{1} \frac{\mathrm{dS}}{\mathrm{dt}}
$$

This corrected signal (Fig. 9, dashed line) now approaches the asymptotic height more quickly, but still shows evidence of a exponential decay for intermediate time. Indeed, a plot of $\ln \left(1-\mathrm{S}_{1}[\mathrm{t}]\right)$ vs $\mathrm{t}$ (Fig. 10, dashed line) asymptotes to a straight line, with slope corresponding to a second characteristic time $\tau_{2}$ 


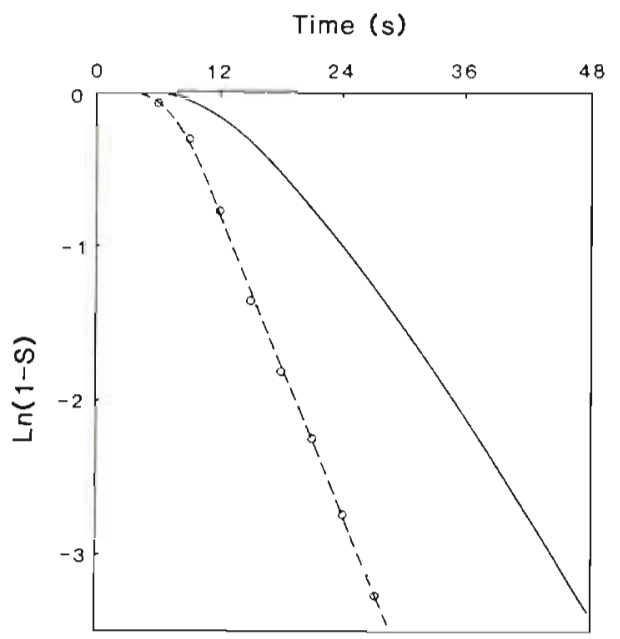

Fig. 10. Transformated signals $\ln (1-\mathrm{S}[\mathrm{t}]$ ) (solid line) and $\ln \left(1-\mathrm{S}_{1}[\mathrm{t}]\right)$ (dashed line) vs time

$=5.7 \mathrm{~s}$. As before, $\tau_{2}$ can be used to correct $S_{1}(t)$ to obtain a signal $\mathrm{S}_{2}(\mathrm{t})$ :

$$
\mathrm{S}_{2}(\mathrm{t})=\mathrm{S}_{1}(\mathrm{t})+\tau_{2} \frac{\mathrm{dS}}{\mathrm{dt}}
$$

and the calculated values of this signal are indicated by the solid dots in Fig. 9. This signal shows no evidence of an exponential approach, and can be well approximated by a cumulative gaussian with a standard deviation of $2.6 \mathrm{~s}$ (Fig. 9, triangles). This kind of smearing was predicted by Taylor (1953) for slow flow through tubes.

According to this analysis, the autoanalyzer signal is obtained from the input signal by 3 successive linear operations: 2 first-order processes with characteristic times of 9.8 and $5.7 \mathrm{~s}$ and a diffusive process with a standard deviation of $2.6 \mathrm{~s}$. These can be written explicitly as integral operators:

$$
\mathrm{S}=\mathrm{L}_{1} \mathrm{~L}_{2} \mathrm{~L}_{3} \mathrm{~S}_{\mathrm{i}}
$$

where $L_{j} S(t)=\left\{\int_{-\infty}^{t} e^{(s-t) \tau,} S(s) d s\right\} / \tau_{j} \quad j=1,2$

$$
\mathrm{L}_{3} \mathrm{~S}(\mathrm{t})=\left\{\int_{-\infty}^{\infty} \mathrm{e}^{-(\mathrm{s}-\mathrm{t})^{2} / 2 \sigma^{2}} \mathrm{~S}(\mathrm{~s}) \mathrm{ds}\right\} /\left(2 \pi \sigma^{2}\right)^{0.5}
$$

We assume that the smearing effect of the valve and filter can be represented by a first-order linear operator $\mathrm{L}_{4}$. The signal corresponding to a step-change in concentration with valve and filter in line will then be given by

$$
\mathrm{S}_{\mathrm{f}}=\mathrm{L}_{1} \mathrm{~L}_{2} \mathrm{~L}_{3} \mathrm{~L}_{\mathrm{f}} \mathrm{S}_{1}
$$

One could try to obtain $\mathrm{L}_{f} \mathrm{~S}_{1}$ explicitly by inverting $\mathrm{L}_{1}$, $L_{2}$ and $L_{3}$. However, inverting $L_{1}$ and $L_{2}$ in succession produces considerable noise in the result (Fig. 9), and the inversion of $\mathrm{L}_{3}$ is particularly error prone. Fortunately, there is a simpler and more accurate alternative which relies on the fact that the linear operators $L_{1}, L_{2}$,
$L_{3}$ and $L_{f}$ all commute: that is, the order in which they are applied does not affect the result. One can therefore write:

$$
\begin{aligned}
\mathrm{S}_{\mathrm{f}} & =\mathrm{L}_{\mathrm{f}}\left(\mathrm{L}_{1} \mathrm{~L}_{2} \mathrm{~L}_{3} \mathrm{~S}_{\mathrm{i}}\right) \\
& =\mathrm{L}_{\mathrm{f}} \mathrm{S}
\end{aligned}
$$

This in turn can be written as:

$$
\frac{d S_{f}}{d t}=\left(S-S_{f}\right) / \tau_{f}
$$

A plot of $\frac{d S_{f}}{d t}$ vs $S-S_{f}$ should then be a straight line with slope $1 / \tau_{i}$. This plot is very well approximated by a straight line (Fig. 11), with a correlation coefficient of 0.999 and a slope corresponding to $\tau=3.3 \mathrm{~s}$. The

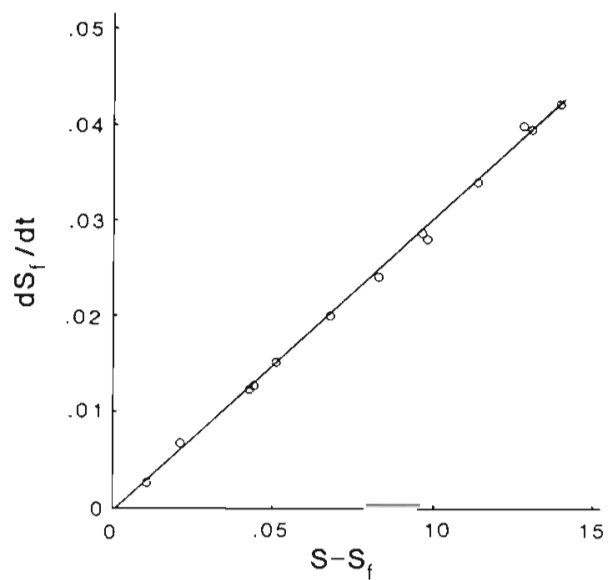

Fig. 11. $\frac{d S_{f}}{d t}$ vs $S-S_{f}$, where $S_{f}$ and $S$ are responses to a unit step change with and without the filter and valve in line. The straight line represents a linear regression and has a slope of $0.30 \mathrm{~s}^{-1}$

actual shape of the $15 \mathrm{~s}$ pulse seen by cells on the filter can then be obtained by applying the operator $L_{f}$ to a 15 s square wave. The result (Fig. 7) is not smeared badly enough to distort $15 \mathrm{~s}$ uptake rates greatly.

Having characterized the autoanalyzer response, we attempted to obtain instantaneous uptake rate estimates by applying the inverse of the operators $\mathrm{L}_{1}, \mathrm{~L}_{2}, \mathrm{~L}_{3}$ to the difference between pulses with and without cells on the filter. The first-order operators can be inverted by the procedure described above. The gaussian operator cannot be inverted in the same way, but it has a narrow window $(\sigma=2.6$ s) so that, even without correcting for it, one can obtain a time resolution of about $10 \mathrm{~s}$. The successive inversion of the linear operators, as in Fig. 9, is equivalent to the addition of first and second derivatives to the original data, and introduces considerable scatter. In addition, uncertainties in aligning exactly the $t=0$ points for pulses with and without cells on the filter can severely distort 
estimates of uptake rate over the first few seconds. This uncertainty was reduced by using $1 \mathrm{~min}$ pulses and forcing uptake rates to behave reasonably during the decline phase. Corrected 1 min pulses with and without cells on the filter, and the corresponding uptake rate estimates, are shown in Fig. 8, for standards ranging from 0.3 to $8 \mu \mathrm{M}$.

\section{LITERATURE CITED}

Cembella, A. D., Antia, N. J., Harrison, P. J. (1984). The utilization of inorganic and organic phosphorus compounds as nutrients by eukaryotic microalgae: a multidisciplinary perspective: Part 1 Cleveland Rubber Co. crit. Rev. Microbiol: 10: 317-391

Conway, H. L., Harrison, P. J., Davis, C. O. (1976). Marine diatoms grown in chemostats under silicate or ammonium limitation. II. Transient responses of Skeletonema costatum to a single addition of the limiting nutrient. Mar. Biol. 35: 187-199

Goldman, J. C., Glibert, P. M. (1982). Comparative rapid ammonium uptake by four species of marine phytoplankton. Limnol. Oceanogr. 27: 814-827

Harrison, P. J., Waters, R. E., Taylor, F. J. R. (1980). A broad spectrum artificial seawater medium for coastal and open ocean phytoplankton. J. Phycol. 16: 28-35
McCarthy, J. J. (1981). The kinetics of nutrient utilization. Can. Bull. Fish. Aquat. Sci. 210: 211-233

Parslow, J. S., Harrison, P. J., Thompson, P. A. (1984a). Use of a self-cleaning, in-line filter to continuously monitor phytoplankton nutrient uptake rates. Can. J. Fish. Aquat. Sci. 41: $540-544$

Parslow, J. S., Harrison, P. J., Thompson, P. A. (1984b). Development of rapid ammonium uptake during starvation of batch and chemostat cultures of a marine diatom Thalassiosira pseudonana. Mar. Biol. 83: 43-50

Parslow, J. S., Harrison, P. J., Thompson, P. A. (1985). Interpreting rapid changes in uptake kinetics in the marine diatom Thalassiosira pseudonana (Hustedt). J. exp. mar. Biol. Ecol. (in press)

Pasciak, W. J., Gavis, J. (1974). Transport limitation of nutrient uptake in phytoplankton. Limnol. Oceanogr. 19: 881-888

Raven, J. A. (1980). Nutrient transport in microalgae. Adv. microb. Physiol. 21: 47-226

Taylor, G. (1953). Dispersion of soluble matter solvent flowing slowly through a tube. Proc. R. Soc. Lond. A 219: 186-203

Wheeler, P. A. (1983). Phytoplankton nitrogen metabolism. In: Carpenter, E. J., Capone, D. G. (ed.) Nitrogen in the marine environment. Academic Press, New York, p. 309-346

Whitledge, T. E., Malloy, S. C., Patton, C. J., Wirick, C. D. (1981). Automated nutrient analyses in seawater. Brookhaven Nat. Lab., U.S. Dept. Energy and Environment 